\title{
An optimised age-based dosing regimen for single low-dose primaquine for blocking malaria transmission in Cambodia
}

Rithea Leang ${ }^{1}$, Naw Htee Khu ${ }^{2}$, Mavuto Mukaka ${ }^{2,3}$, Mark Debackere ${ }^{4}$, Rupam Tripura2, Soy Ty Kheang ${ }^{5}$, Say Chy ${ }^{5}$, Neeraj Kak ${ }^{6}$, Philippe Buchy ${ }^{7}$, Arnaud Tarantola ${ }^{7}$, Didier Menard ${ }^{7}$, Arantxa Roca-Felterer ${ }^{8}$, Rick M. Fairhurst ${ }^{9}$, Sim Kheng ${ }^{1}$, Sinoun Muth ${ }^{1}$, Song Ngak ${ }^{10}$, Arjen M. Dondorp ${ }^{2,3}$, Nicholas J. White ${ }^{2,3}$

and Walter Robert John Taylor 2,3,1 1*

\begin{abstract}
Background: In 2012, the World Health Organization recommended the addition of single low-dose primaquine (SLDPQ, $0.25 \mathrm{mg}$ base/kg body weight) to artemisinin combination therapies to block the transmission of Plasmodium falciparum without testing for glucose-6-phosphate dehydrogenase deficiency. The targeted group was non-pregnant patients aged $\geq 1$ year (later changed to $\geq 6$ months) with acute uncomplicated falciparum malaria, primarily in countries with artemisinin-resistant $P$. falciparum (ARPf). No dosing regimen was suggested, leaving malaria control programmes and clinicians in limbo. Therefore, we designed a user-friendly, age-based SLDPQ regimen for Cambodia, the country most affected by ARPf.

Methods: By reviewing primaquine's pharmacology, we defined a therapeutic dose range of $0.15-0.38 \mathrm{mg}$ base/ $\mathrm{kg}(9-22.5 \mathrm{mg}$ in a $60-\mathrm{kg}$ adult) for a therapeutic index of 2.5 . Primaquine doses $(1-20 \mathrm{mg})$ were tested using a modelled, anthropometric database of 28,138 Cambodian individuals (22,772 healthy, 4119 with malaria and 1247 with other infections); age distributions were: $0.5-4$ years $(20.0 \%, n=5640), 5-12$ years $(9.1 \%, n=2559), 13-17$ years $(9.1 \%, n=2550)$, and $\geq 18$ years $(61.8 \%, n=17,389)$. Optimal age-dosing groups were selected according to calculated $\mathrm{mg}$ base/kg doses and proportions of individuals receiving a therapeutic dose.
\end{abstract}

Results: Four age-dosing bands were defined: (1) 0.5-4 years, (2) 5-9 years, (3) 10-14 years, and (4) $\geq 15$ years to receive $2.5,5,7.5$, and $15 \mathrm{mg}$ of primaquine base, resulting in therapeutic doses in $97.4 \%$ (5494/5640), $90.5 \%$ (1511/1669), $97.7 \%$ (1473/1508), and $95.7 \%(18,489 / 19,321)$ of individuals, respectively. Corresponding median (1st-99th centiles) $\mathrm{mg}$ base/kg doses of primaquine were (1) 0.23 (0.15-0.38), (2) 0.29 (0.18-0.45), (3) 0.27 (0.15-0. 39), and (4) $0.29(0.20-0.42)$.

Conclusions: This age-based SLDPQ regimen could contribute substantially to malaria elimination and requires urgent evaluation in Cambodia and other countries with similar anthropometric characteristics. It guides primaquine manufacturers on suitable tablet strengths and doses for paediatric-friendly formulations. Development of similar age-based dosing recommendations for Africa is needed.

Keywords: Primaquine, Malaria, G6PD deficiency, Dosing, Cambodia

\footnotetext{
* Correspondence: bob@tropmedres.ac

${ }^{2}$ Mahidol Oxford Tropical Medicine Research Unit (MORU), 420/6 Rajvithi Road, Rajthevee, Bangkok 10400, Thailand

${ }^{3}$ Oxford Centre for Tropical Medicine and Global Health, Nuffield Department

of Medicine Research Building, University of Oxford, Old Road Campus,

Roosevelt Drive, Oxford OX3 7FZ, UK

Full list of author information is available at the end of the article
} 


\section{Background}

In September 2012, the World Health Organization (WHO) Evidence Review Group recommended adding single low-dose primaquine (SLDPQ, $0.25 \mathrm{mg}$ base $/ \mathrm{kg}$ body weight, $15 \mathrm{mg}$ for adults) to artemisinin combination therapies (ACTs), without testing for glucose-6-phosphate dehydrogenase deficiency (G6PDd), in non-pregnant, falciparum-infected patients aged $\geq 1$ year (later amended to $\geq 6$ months) to block Plasmodium falciparum gametocyte transmission from humans to mosquitoes [1, 2]. This recommendation was aimed primarily at countries of the Greater Mekong Subregion (GMS) where artemisininresistant $P$. falciparum (ARPf) is well established and continues to emerge [3-9]. Indeed, ARPf is now at the threshold of the Indian subcontinent [10].

The 2012 recommendation was pragmatic, taking into account the lack of detailed, carefully conducted doseoptimisation studies of primaquine (PQ), the reluctance to use PQ in the GMS because of the fear of PQinduced acute haemolytic anaemia (AHA) in G6PDd patients, the logistical impossibility of testing widely for G6PDd, and the urgency to eliminate ARPf in the GMS. There is now convincing evidence that increasing treatment failures of dihydroartemisinin-piperaquine (DHAPP), the first-line ACT in Cambodia, is due to a combination of ARPf and PP resistance and that ARPf has probably contributed to the rapidly evolving ineffectiveness of this ACT [11-14]. More ACT failures can be expected in areas of ARPf and this alarming scenario underscores the urgency to eliminate falciparum malaria from the GMS.

Aside from Vietnam, which uses $0.75 \mathrm{mg}$ base $/ \mathrm{kg}$ of $\mathrm{PQ}$, countries in the GMS have been slow to recommend SLDPQ, but attitudes are changing. In August 2015, Cambodia decided to deploy SLDPQ thanks, in part, to reassuring data on the use of $0.75 \mathrm{mg}$ base $/ \mathrm{kg}$ of weekly PQ (45 mg in a $60-\mathrm{kg}$ adult) in vivax-infected G6PDd patients [15]. Moreover, a pilot study of SLDPQ is being conducted in acute uncomplicated falciparum malaria (ClinicalTrials.gov identifier, NCT02434952) and SLDPQ is being included in antimalarial drug resistance studies (NCT02453308).

When countries agree to adopt SLDPQ, one fundamental question is how the recommended dose is translated into a practical dosing regimen. No PQ dosing regimen was suggested in the 2012 recommendation. The 2015 WHO Malaria Treatment Guidelines (http:// www.who.int/malaria/publications/atoz/9789241549127/ en/) contain a weight-based regimen using whole and fractions of a 7.5-mg PQ base tablet; it is unclear what evidence informed this regimen. Weight-based regimens that require tablet fractions are a major hassle for care providers and result in poor dosing accuracy [16].

In Cambodia, approximately one-third of malaria patients receive treatment through Cambodia's network of village malaria workers, who do not have weighing scales (D. Soley, personal communication), thus limiting the impact of weight-based regimens. Moreover, Cambodian patients frequently buy drugs from market stalls and village drug shops $[17,18]$, a common practice seen in other malaria-endemic countries $[19,20]$. The PQ dosing conundrum is not new and one solution is to design easy to use, optimised, age-based dosing regimens, as has been done for artesunate-amodiaquine [21], artesunatemefloquine, and DHAPP.

Designing such regimens is not straightforward. Many elements must be considered carefully, including drug pharmacokinetics (PK) and pharmacodynamics (PD, i.e. efficacy and toxicity), PK-PD relationships, simplicity of use, and anthropometric differences between countries $[21,22]$. Ultimately, the crucial determination is the mg base/kg dosing therapeutic range. Dosing within the range is considered optimal but underdosing or supratherapeutic doses risk low efficacy and dose-dependent drug toxicity, respectively. Drugs with lower therapeutic indices offer less dosing flexibility. Herein, we propose an agebased SLDPQ regimen for Cambodia and report on how we arrived at this regimen.

\section{The efficacy of low-dose $P Q$ in reducing mosquito infectivity}

Since the 1920s, pioneering work in falciparum malaria patients showed that low doses of the 8-aminioquinoline plasmochin/e (also known as pamaquine/plasmoquine) rapidly reduced mosquito infectivity (typically $\leq 24 \mathrm{~h}$ ), well before the 3-4 days it took to clear gametocytes $[23,24]$. Moreover, recent data from Mali has shown no relationship between gametocyte density and infectivity after PQ administration [25]. Thus, gametocyte parameters should be considered weak surrogate markers of mosquito infectivity [26].

In the 1960s, limited data in naturally- [27] and experimentally-acquired [28] falciparum malaria showed that $15 \mathrm{mg}$ of PQ (i.e. SLDPQ) reduced mosquito infectivity to a similar degree as $45 \mathrm{mg}$ of $\mathrm{PQ}$, but the latter became the WHO-recommended dose. Data from P. falciparum-infected, DHAPP-treated, Vietnamese and Cambodian adults show a curvilinear response between PQ dose (3.7-15 mg base) and mosquito infectivity, assessed by mosquito membrane feeding assays [1]; $7.5 \mathrm{mg}$ of PQ base $(0.125 \mathrm{mg}$ base $/ \mathrm{kg}$ in a $60-\mathrm{kg}$ individual) provided almost maximal transmission blocking, suggesting this dose is close to the minimum dose that produced the maximum effect the minimum transmission-blocking (MTB) dose. Support that $0.125 \mathrm{mg}$ base $/ \mathrm{kg}$ is close to the MTB comes from mosquito membrane feeding assays in DHAPP-treated, P. falciparum-infected Malians (Fig. 1), in whom the MTB was between 0.125 and $0.25 \mathrm{mg}$ base $/ \mathrm{kg} ; 0.0625 \mathrm{mg}$ base/ $\mathrm{kg}$ was similar to no PQ [25]. 


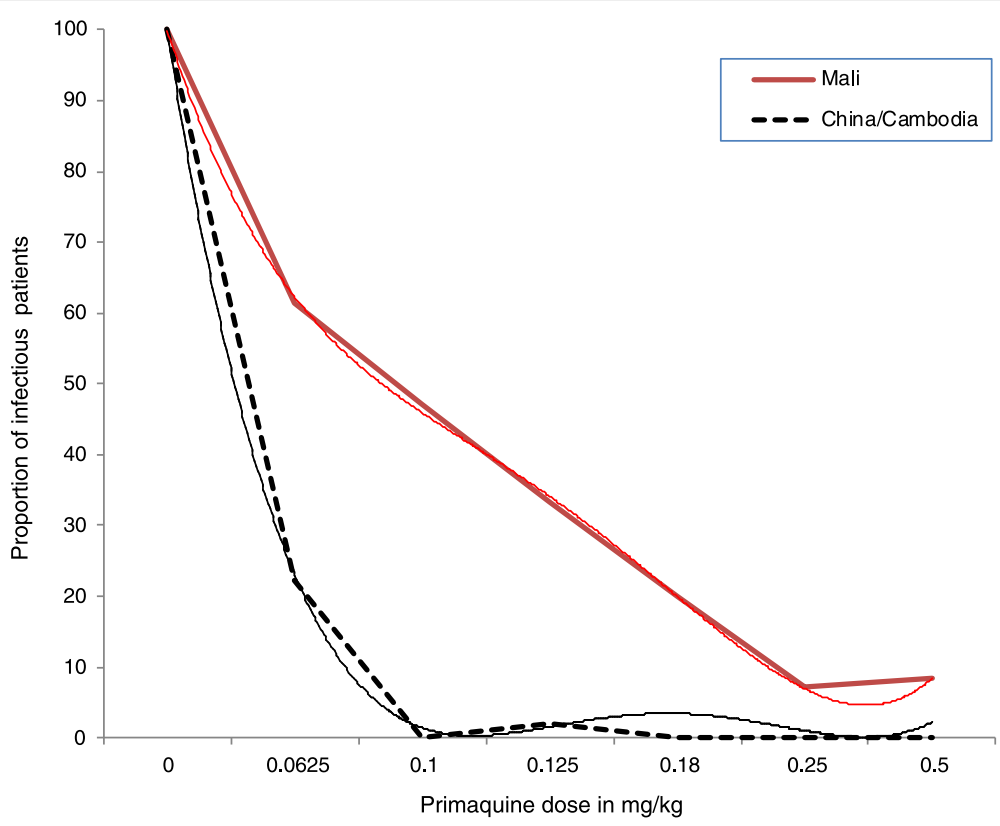

Fig. 1 Mosquito infectivity as a function of administered primaquine dose. The trends have been smoothened using polynomials of order 4 and 6 for Mali and China/Cambodia, respectively. The red line represents Malian patients treated with dihydroartemisinin-piperaquine (DHAPP) [25], and the green line represents Vietnamese and Cambodian adults treated with DHAPP [1]

Data from mass drug administration (MDA) in 17 Cambodian villages using an initial dose of artemisininpiperaquine plus $9 \mathrm{mg}$ of $\mathrm{PQ}(0.15 \mathrm{mg}$ base $/ \mathrm{kg}$ in a $60 \mathrm{~kg}$ person) followed by PQ administered every 10 days for 6 months reduced malaria prevalence rates over 3 years [29]. Although lacking a control group, mathematical modelling supported the reduction in $P$. falciparum transmission with this PQ regimen [30]. Based on these efficacy data, the MTB dose of PQ lies between 0.125 and $0.15 \mathrm{mg} / \mathrm{kg}$ of PQ base.

\section{Primaquine tolerability and safety}

An extensive review of PQ's safety has shown that it is very well tolerated. Deaths are extremely rare and associated with repeated PQ doses [31]. However, there are few data on SLDPQ and very limited data on PQ in South East Asian variants of G6PDd.

G6PDd, an X-linked inherited red blood cell enzymopathy affecting 400 million people, is a major public health challenge to malaria elimination because PQinduced AHA is dose-dependent and related to the degree of enzyme deficiency [32, 33]. Therefore, hemizygous males $\left(\mathrm{X}^{*} \mathrm{Y}\right)$ and homozygous females $\left(\mathrm{X}^{*} \mathrm{X}\right.$ ) generally suffer greater AHA compared to heterozygous females $\left(\mathrm{X}^{*} \mathrm{X}\right)$, and AHA is milder in the African Avariant compared to more severe G6PDd variants such as Mediterranean, Viangchan, Mahidol, Canton, and Hong Kong-Pokfulam [34-38]. Recognising the paucity of safety data, the WHO Evidence Review Group relied on expert opinion, stating "we expect that a single $15 \mathrm{mg}$ $P Q$ adult dose $(0.25 \mathrm{mg}$ base $/ \mathrm{kg})$ will not result in clinicallysignificant haemolysis in G6PD-deficient individuals" http://www.who.int/malaria/mpac/sep2012/primaquine_ single_dose_pf_erg_meeting_report_aug2012.pdf?ua $=1$.

In Cambodia, approximately $90 \%$ of G6PDd is due to the Viangchan variant, which has a median enzyme activity of $0.8 \mathrm{U} / \mathrm{gHb}(\sim 7 \%$ of the population median of $12 \mathrm{U} /$ $\mathrm{gHb})$, placing it at the severe end of the G6PDd spectrum $[39,40]$. AHA induced by $15 \mathrm{mg}$ of daily PQ alone was well tolerated in healthy Cambodian Air Force men who had a mean baseline haemoglobin concentration of approximately $14 \mathrm{~g} / \mathrm{dL}$ and which fell by a mean of $21 \%$ on day (D)7, persisting to D15 [37]. Data in vivax-infected patients, with $\mathrm{Hb}$ concentrations $\geq 10 \mathrm{~g} / \mathrm{dL}$, showed that weekly-administered $0.75 \mathrm{mg}$ base $/ \mathrm{kg}$ of PQ resulted in a greater $\mathrm{Hb}$ level decline in G6PDd compared to G6PD normal patients. The greatest fractional fall in $\mathrm{Hb}$ occurred on $\mathrm{D} 7$ (median (range)): $-16.3 \%$ ( -33.1 to 6.5$)$ versus $-3.7 \%$ ( -17.5 to 23.3) for corresponding absolute $\mathrm{Hb}$ concentration falls of $-2.2 \mathrm{~g} / \mathrm{dL}$ ( -4.9 to 0.8 ) versus $-0.5 \mathrm{~g} / \mathrm{dL}$ ( -2.2 to 2.8 ) [15].

The PQ dose-AHA response curve in G6PDd individuals is unknown, but the more severe variants will have a steeper slope because they are more sensitive to PQ's oxidative effects [32]. Extrapolating the $\mathrm{Hb}$ data from the vivax-infected Cambodians and assuming similar $\mathrm{Hb}$ dynamics in patients with falciparum and vivax malaria [41], $0.38 \mathrm{mg} / \mathrm{kg}$ of PQ base (i.e. approximately half the dose given to the vivax malaria patients) might result in 
a fractional decline of up to approximately $-20 \%$ (approximately $-2.5 \mathrm{~g} / \mathrm{dL}$ ). This decline should be well tolerated and is consistent with $\mathrm{Hb}$ declines seen in falciparum malaria patients in South East Asia, where approximately $60 \%$ of ACT-treated falciparum malaria patients (with unknown G6PD status) have fractional declines in $\mathrm{Hb}$ of $<0$ to $-20 \%$, and $12 \%$ have a decline exceeding $-20 \%$ (W. Taylor, unpublished observations).

However, approximately 5 and $12 \%$ of Cambodian patients with acute uncomplicated falciparum or vivax malaria have $\mathrm{Hb}$ concentrations $<5$ and $<7 \mathrm{~g} / \mathrm{dL}$, respectively (analysis from [41]); most are treated as outpatients with oral ACTs. The effect of SLDPQ in such patients with G6PDd remains unknown and demands caution in setting the upper end of the therapeutic dose range.

MDA data from villages on the Thai-Burmese border show that G6PDd and G6PD normal, healthy individuals had small declines in mean $\mathrm{Hb}$ of approximately $-5 \%$ and $-1 \%$, respectively, when given DHAPP plus SLDPQ, the latter dosed exactly at $0.25 \mathrm{mg}$ base $/ \mathrm{kg}$ [42]. These data are reassuring for MDA but are not generalisable to malaria patients.

Methaemoglobinaemia (metHb, upper limit of normal approximately $2-3 \%$ ) is a dose-dependent side effect of PQ but is not considered a clinical worry because, in vivax infected patients, $0.75 \mathrm{mg}$ base $/ \mathrm{kg}$ of PQ resulted in a maximum metHb concentration of $4.9 \%$, a concentration that was well tolerated [15]; thus, $0.25 \mathrm{mg} / \mathrm{kg}$ of $\mathrm{PQ}$ is likely to result in very small increases in metHb. Abdominal pain, also dose-related, is reduced by food intake $[43,44]$ and was not an important symptom when $30 \mathrm{mg}$ of PQ was given daily with a small snack for 1 year in Indonesian adults [45].

\section{PQ pharmacokinetics}

PQ is readily absorbed from the gastrointestinal tract $[46,47]$ and undergoes hepatic oxidative deamination to its principal, inactive metabolite, carboxyprimaquine (cPQ), chiefly by monoamine oxidase (MAO) A $[48,49]$. Cytochrome (CYP) P450 isoenzymes 2D6, 2C19, and 3A4 are quantitatively less important than MAO A, but CYP 2D6 is fundamental to the PD effects of PQ because this pathway produces oxidative metabolites (OMs) that are responsible for AHA [50-54], dose-dependent oxidation of $\mathrm{Hb}[55,56], \mathrm{PQ}$ 's antirelapse efficacy $[48,57]$ and, probably, its gametocytocidal effect.

OM concentrations are very low, unstable, and difficult to measure; thus, their PK profiles and their PK-PD relationships remain undocumented [48]. This is a considerable drawback because inferences about the PK characteristics of OMs are based on the PK characteristics of PQ and $C P Q$, neither of which is pharmacologically important for transmission blocking $[58,59]$.
CYP 450 2D6 activity is under polymorphic genetic control resulting in several metabolic patterns: poor (poor efficacy, less dose-related toxicity), intermediate, extensive (normal), and ultrarapid/ultraextensive (potentially enhanced efficacy and dose-related toxicity) [60]. The genetic bases for the metabolic phenotypes are complex and their clinical predictive value unclear [61, 62].

The population prevalence rates of the CYP 2D6 polymorphisms are unknown in Cambodia, but data from 125 P. falciparum-infected Cambodians found allele frequencies for CYP 2D6*4 (poor activity/metabolisers), 2D6*10 (intermediate), and 2D6*17 (intermediate) of 0 , approximately $63 \%$ and $4 \%$, respectively [63]. Although these data are in broad agreement with other small studies $[64,65]$, predicting the PD effects of SLDPQ at the population level remains problematic.

$\mathrm{PQ}$ and $\mathrm{CPQ}$ exposures, measured as the area under the concentration time curve, are linearly dose-related [47, 66]. The inter-individual variation in $\mathrm{PQ}$ and $\mathrm{CPQ}$ exposure generally ranges from approximately 1.75-4 [46, 67-69]. One study in healthy G6PD normal children aged 5-12 years from Papua New Guinea found PQ-PK characteristics equivalent to those in adults [66]. This is a potentially significant finding because a failure to appreciate that children have higher clearance rates of some antimalarial drugs compared to adults has resulted in under dosing of sulfadoxine-pyrimethamine and DHAPP [70, 71]. The Papua New Guinea data support the use of the same $\mathrm{mg}$ base $/ \mathrm{kg}$ dose range for adults and children as young as 5 years and should result in comparable OM exposures.

PQ-PK parameters are similar between healthy volunteers and vivax malaria patients, Thais and Caucasians, and are unaffected by G6PD status [46, 47, 72-74]; data on sex differences are inconsistent $[46,74,75]$. PQ and CPQ exposures are increased by falciparum malaria (reduced PQ clearance) [69], food (26\% when given with bread and butter (28 $\mathrm{g}$ of fat)) [46], and chloroquine (PQ $24 \%$, cPQ $14 \%$ ) and DHAPP (PQ $25 \%$, cPQ $9 \%$ ), which could have competed for CYP 3A4, thereby diverting more $\mathrm{PQ}$ to the MAO A and, presumably, 2D6 pathways $[67,68]$. There is no PK interaction between PQ and either artesunate-pyronaridine [76] or mefloquine $[69,77]$; no PK interaction data exist for PQ and artemether-lumefantrine (AL).

Extrapolating from the above, OM PK characteristics will probably depend mostly on PQ dose and absorption and CYP 2D6 metabolic status; thus, selecting the lower $\mathrm{mg} / \mathrm{kg}$ dose of PQ base should ensure that the majority of patients will achieve adequate OM concentrations to reduce infectivity.

\section{Artemisinin-resistant Plasmodium falciparum malaria}

ARPf results in slower killing of asexual forms, leading to increased gametocytogenesis. Falciparum malaria patients 
from areas of ARPf in western Cambodia (Pailin and Pursat) had a higher risk $(P<0.01)$ of gametocytaemia at presentation (18.6\%) and on D7 (16.3\%) compared to patients from either northern (Preah Vihear) or eastern (Ratanakiri) Cambodia (5.4 and 4.8\%, respectively) [8].

However, at baseline, gametocytaemia distributions (median (interquartile range)) in patients with patent gametocytaemia were not significantly different $(P=0.44)$ between western $(32(16-176) / \mu \mathrm{L})$ and eastern/northern (64 (32-144) $/ \mu \mathrm{L}$ ) Cambodia (E. Ashley, unpublished observations). Therefore, it seems likely that, for now, SLDPQ should be equally effective at killing gametocytes and reducing infectivity independent of ARPf, recognising the limitations of gametocytaemia for predicting infectivity.

\section{Defining the PQ therapeutic dose range}

The recommended target dose of PQ is $0.25 \mathrm{mg}$ base $/ \mathrm{kg}$ given once with an ACT. In practice, exact dosing is not possible and some patients will receive $\mathrm{mg}$ base $/ \mathrm{kg}$ doses above or below the target dose. The questions to address when setting a therapeutic limit are (1) how many patients are likely to receive an ineffective PQ dose, and (2) how many patients would experience symptomatic AHA?

Given the MTB dose derived from the mosquito infectivity data, the field experience of low-dose PQ, the caution against using too low a dose and the possibility of poor PQ metabolism, we propose the lower end of the therapeutic range to be $0.15 \mathrm{mg}$ base $/ \mathrm{kg}(9 \mathrm{mg}$ in a $60-\mathrm{kg}$ adult). Considering the $\mathrm{Hb}$ data in the $P$. vivax-infected G6PDd patients, we propose an upper dose of $0.38 \mathrm{mg}$ base $/ \mathrm{kg}$ (22.5 $\mathrm{mg}$ in a $60-\mathrm{kg}$ adult). These limits translate into a therapeutic index of 2.5.

\section{Methods}

\section{Assembling the Cambodian anthropometric database}

After obtaining permission from the Demographic Health Survey (DHS), the 2014 DHS Cambodian database was downloaded from the DHS web site (http:// www.measuredhs.com). The database contains a broad range of data collected randomly. The data of prime interest were available in children aged $<60$ months and women aged 15-45 years: (1) age (years and months for children $<60$ months), (2) weight to one decimal place, (3) sex, (4) pregnancy status, (5) residential address, and (6) whether the residence was rural or urban.

Other databases, obtained from colleagues at the Centre National de Malariologie and several of its collaborators, consisted of malaria patients, field surveys of individuals in malaria-endemic villages, patients with suspected central nervous system (CNS) infections, and individuals with dog bites who presented to l'Institut Pasteur du Cambodge Rabies Prevention Centre in Phnom Penh.
Colleagues and collaborators were first asked by WRJT if they would be willing to send relevant, anonymised anthropometric, demographic, and geographical data. They were informed why these data were being sought and that those who freely gave data would be co-authors on this paper.

Obtaining ethical clearance was not generally considered relevant for this study because most data (DHS) were already in the public domain, the dog bite data were routine clinic data, and the rest of the data were from studies approved by the National Ethical Committee for Health Research of the Cambodian Ministry of Health. In some studies, patients provided consent for secondary analyses so long as they were related to malaria. The Oxford Tropical Research Ethics Committee confirmed that this study was exempt from ethical review.

\section{Modelling the weight-for-age data}

The raw weight-for-age data were modelled into a growth curve (Additional file 1: Figure S1) by firstly excluding outlying weights for age; these were defined as values falling outside of the 1st and 99th centiles, using Box Cox power exponential model centiles. This resulted in 795 individuals being excluded from the database (Fig. 2). In order to obtain the weight-for-age centiles, the data were modelled using the three-parameter Box Cox power exponential distribution [78] and the centile growth curves smoothed using the cubic spline smoothing technique [79]. The modelling was performed in Stata using the 'xriml' macro Stata module [78] with cubic spline. Although the 95th or 97.7th percentiles $[80,81]$ are used as cut-offs for excluding overweight individuals (outliers), we used the conservative 1st and 99th percentiles for the exclusion of outliers to allow for more generalisability of the curve for PQ dosing in the South East Asian population. In other words, our conservative approach excluded only $2 \%$ of individuals as outliers compared to $5 \%$ or $10 \%$ in other studies.

Ages $\geq 12$ months were rounded down, e.g. a child aged 15 months was rounded down to 1 year; ages $<12$ months were expressed as a decimal of 1 year. The $\mathrm{mg}$ base/ $\mathrm{kg}$ dose of PQ received for a given age group was calculated by simple division: $\mathrm{PQ}$ dose/all the weights for that age group.

\section{Data analysis and determining optimal age-dosing categories}

Within each age-dosing group, we calculated the proportions of males and females, individually and combined, who would receive therapeutic doses; malefemale differences were compared by the $x^{2}$ test. Differences in the distribution of skewed data were compared using the Mann-Whitney $U$ test and mean differences 


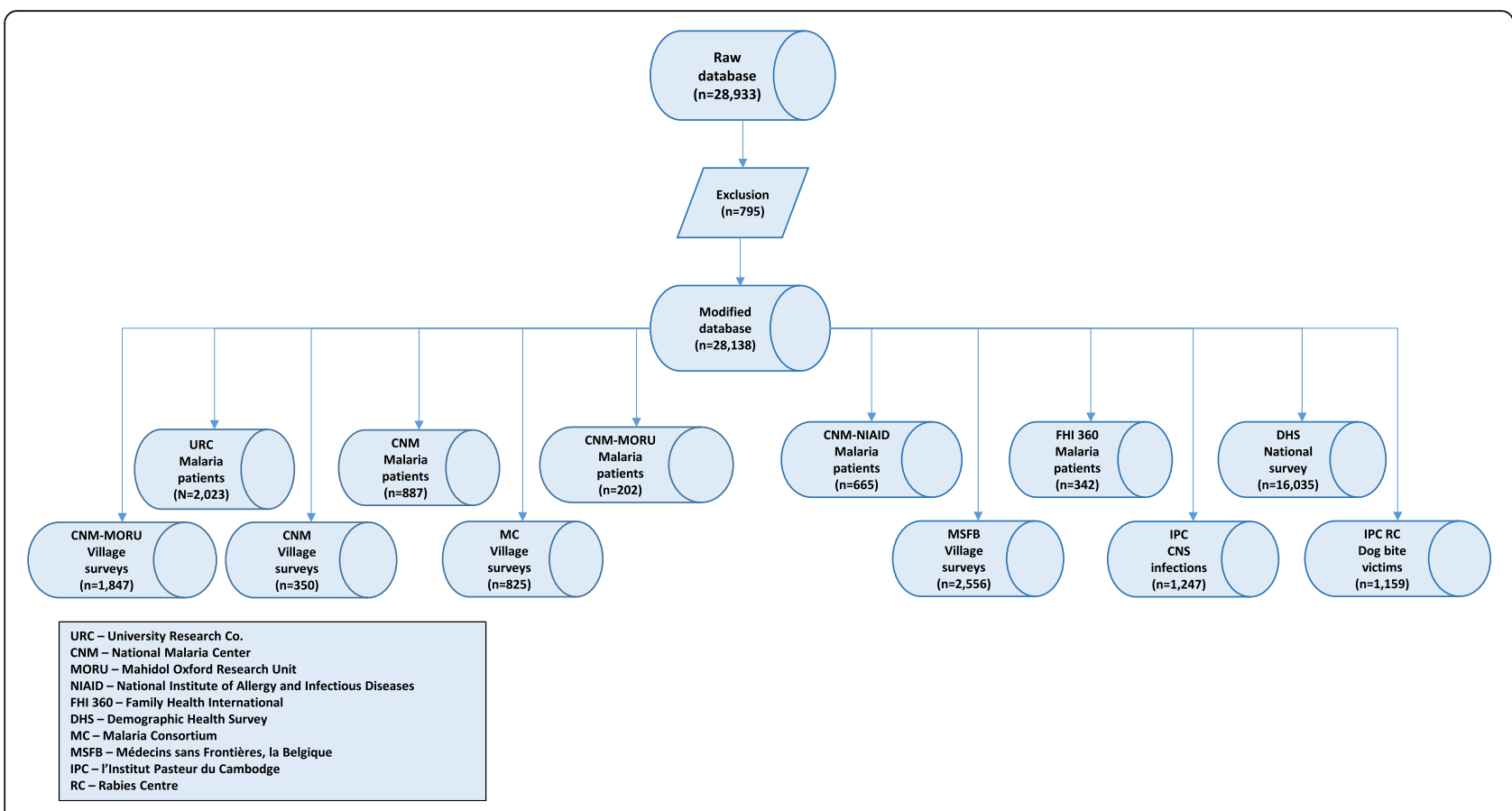

Fig. 2 Database structure

in normally distributed data were compared using the unpaired ' $\mathrm{t}$ ' test. A $P$ value $\leq 0.05$ was considered statistically significant.

We tested different PQ doses (1-20 mg) using different age groupings and analysed the results as above. The final age categories were selected based on (1) the mg base/kg dose received, (2) the proportions receiving a therapeutic dose, (3) how well a given age-dosing group fitted in with the next age-dosing group, (4) taking into account currently available PQ tablet strengths, even those not produced to Good Manufacturing Practice: 2.5, 5, 7.5 and $15 \mathrm{mg}$ base, and (5) a desire to minimise the number of dosing groups.

When the proportions of patients receiving a therapeutic dose were similar for similar age groupings, preference was given to a supratherapeutic dose over an underdose because the risk of clinically-significant acute haemolysis was considered low, a higher dose may compensate for poor PQ metabolisers, and this strategy would allow for an increase in weight of the population in the future.

\section{Results}

\section{Features of the anthropometric database}

The raw database contained 28,933 individuals aged from birth onwards. After removal of missing data and data modelling, the final database included 28,138 individuals aged $\geq 6$ months; the data sources are shown in Fig. 2. The proportion of females was $65.1 \%(18,314 /$ 28,138); data on sex was missing for 340 individuals
(1.2\%). Children aged $0.5-4,5-12$, and 13-17 years accounted for $20.0 \%(\mathrm{n}=5640), 9.1 \%(2559)$, and $9.1 \%$ (2550) of individuals, respectively, while adults accounted for $61.8 \%(17,389)$. Adults aged $>40-80$ and $>50-80$ years numbered 4318 (15.3\%) and 903 (3.2 \%), respectively.

Excluding the 1247 patients with CNS infections whose location could not be confirmed, the urban:rural ratio was 1:4.1. All 5244 urban dwellers were healthy individuals, whilst 17,528 and 4119 rural dwellers were well and had malaria, respectively. The modelled weightfor-age scatter plots of the malaria patients, DHSsurveyed individuals, CNS infection patients, and dog bite victims overlapped substantially (Additional file 2: Figure S2). Moreover, the mean (standard deviation) weights between urban and rural dwellers were similar: $42.2 \mathrm{~kg}$ (19.4) vs. $40.7 \mathrm{~kg}$ (18.3), respectively, but the small mean difference of $1.5 \mathrm{~kg}$ (95\% CI, 0.9-2.1) was significantly different $(P<0.001)$.

\section{Four optimised dosing groups}

We identified four optimised age dosing groups (Table 1). Overall, $90-97 \%$ of patients would receive a therapeutic dose and the median dose received would range from 0.23 to $0.29 \mathrm{mg} / \mathrm{kg}$ of PQ base.

Optimal PQ dose breakdown by individual ages and sex The proportions of females who would receive a therapeutic dose ranged from $63.2 \%$ (age 5 years) to $100 \%$ (Fig. 3); $10 \%$ or more of individuals aged 0.5 to $<1,5,6$, 
Table 1 Summary of the proportions of individuals who would receive a primaquine (PQ) dose within the defined therapeutic dosing range of $0.15-0.38 \mathrm{mg}$ base $/ \mathrm{kg}$ body weight, an underdose ( $<0.15 \mathrm{mg}$ base $/ \mathrm{kg})$, and a supratherapeutic dose ( $>0.38 \mathrm{mg}$ base $/ \mathrm{kg})$

\begin{tabular}{|c|c|c|c|c|c|c|c|c|c|c|}
\hline \multirow[t]{2}{*}{ Age band, years } & \multicolumn{3}{|c|}{ Weight for age } & \multirow[t]{2}{*}{ PQ dose mg base } & \multirow{2}{*}{$\begin{array}{l}\text { Underdose } \\
\mathrm{n}(\%)\end{array}$} & \multirow{2}{*}{$\begin{array}{l}\text { Therapeutic dose } \\
\text { n (\%) }\end{array}$} & \multirow{2}{*}{$\begin{array}{l}\text { Supratherapeutic dose } \\
\mathrm{n}(\%)\end{array}$} & \multicolumn{3}{|c|}{ PQ mg base/kg } \\
\hline & $1 s t$ & median & 99 th & & & & & $1 s t$ & median & 99th \\
\hline $0.5-4(n=5640)$ & 6.5 & 11.0 & 17.1 & 2.5 & 89 (1.58) & $5,494(97.41)$ & $57(1.01)$ & 0.15 & 0.23 & 0.38 \\
\hline $5-9(n=1669)$ & 11.0 & 17.0 & 28.8 & 5 & $5(0.3)$ & 1,511 (90.53) & $153(9.17)$ & 0.18 & 0.29 & 0. \\
\hline $10-14(n=1508)$ & 19.0 & 28.0 & 49.0 & 7.5 & $8(0.53)$ & $1473(97.68)$ & $27(1.79)$ & 0.15 & 0.27 & 0.39 \\
\hline$\geq 15(n=19,321)$ & 36.0 & 51.1 & 74.9 & 15 & 0 & 18,489 (95.69) & $832(4.31)$ & 0.20 & 0.29 & 0.42 \\
\hline
\end{tabular}

Corresponding $\mathrm{mg}$ base/kg doses of $\mathrm{PQ}$ are shown for the 1st, 50 th (median), and 99th centiles

15 , and 16 years would receive supratherapeutic doses and $\leq 4 \%$ of individuals aged $3,4,9$, and 14 years would be under-dosed (Fig. 4).

The proportion of males who would receive a therapeutic dose ranged from $56.6 \%$ (15 years) to $100 \%$ (Fig. 3); $10 \%$ or more of individuals aged $5,10,15$, and 16 years would receive supratherapeutic doses and $\leq 9 \%$ aged 3,4 , 9, 13, and 14 years would be under-dosed (Fig. 4). Statistically significant results were found for male/female comparisons for ages 0.5 to $<1,4,5,15$, and $\geq 18$ years.

The median mg base $/ \mathrm{kg}$ dose of PQ base ranged from 0.19 (age 4 years) to 0.36 (5 years) for females and 0.18 ( 4 years) to 0.38 (14 years) for males (Figs. 5 and 6). The lowest and highest $\mathrm{mg}$ base $/ \mathrm{kg}$ doses were the same for females and males: $0.12 \mathrm{mg}$ base $/ \mathrm{kg}$ (4 years) and $0.54 \mathrm{mg}$ base $/ \mathrm{kg}$ (15 years).

\section{Weight-based $\mathrm{PQ}$ dosing regimen}

A suggested weight-based dosing chart using weight multiples of 10 or $15 \mathrm{~kg}$ and the same tablet strengths as the age-based regimen was developed. Most dosing categories receive therapeutic doses $(0.15-0.38 \mathrm{mg} / \mathrm{kg}$ of PQ base) except for children who weigh $<10 \mathrm{~kg}$ (Table 2).

\section{Discussion}

This is the first, optimised, age-based regimen for SLDPQ and was developed using a substantial database of some 28,000 Cambodians across the age, sex, urban, and rural spectra. It has four dosing bands that could be adopted by the Centre National de Malariologie and, if suitable, adopted also by other malaria control programmes in the GMS as part of their urgent efforts to control and eliminate ARPf.

The data were obtained from several sources and included data from the two-stage, cluster-randomised nationwide DHS survey, dog bite victims (likely also to be a random sample in Cambodia), village surveys in malaria-endemic areas (some using PCR), and malaria patients. The data from patients with suspected CNS infections are likely to be the most biased samples. However, all of the assembled data overlapped substantially and the difference in weight between urban and rural dwellers was small and not significant.

Symptomatic malaria is a rural disease in Cambodia and affects mostly young adult males who work in forests. However, there are also pools of asymptomatic, submicroscopic falciparum malaria cases (detectable by PCR) affecting all ages and both sexes across many rural regions of Cambodia [82-85]. Our weight-for-age database reflected that epidemiology, containing approximately $80 \%$ rural dwellers, malaria patients, and asymptomatic parasiteinfected individuals. Thus, our dosing regimen is applicable to malaria patients and, if MDA becomes policy, asymptomatic malaria parasite carriers as well.

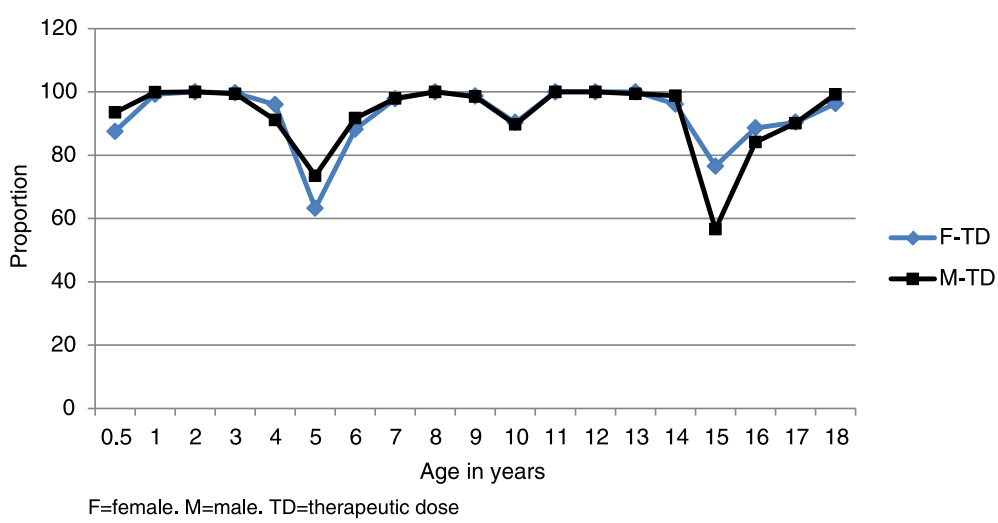

Fig. 3 The proportions of females and males who would receive a therapeutic $(0.15-0.38 \mathrm{mg}$ base $/ \mathrm{kg})$ dose of primaquine 


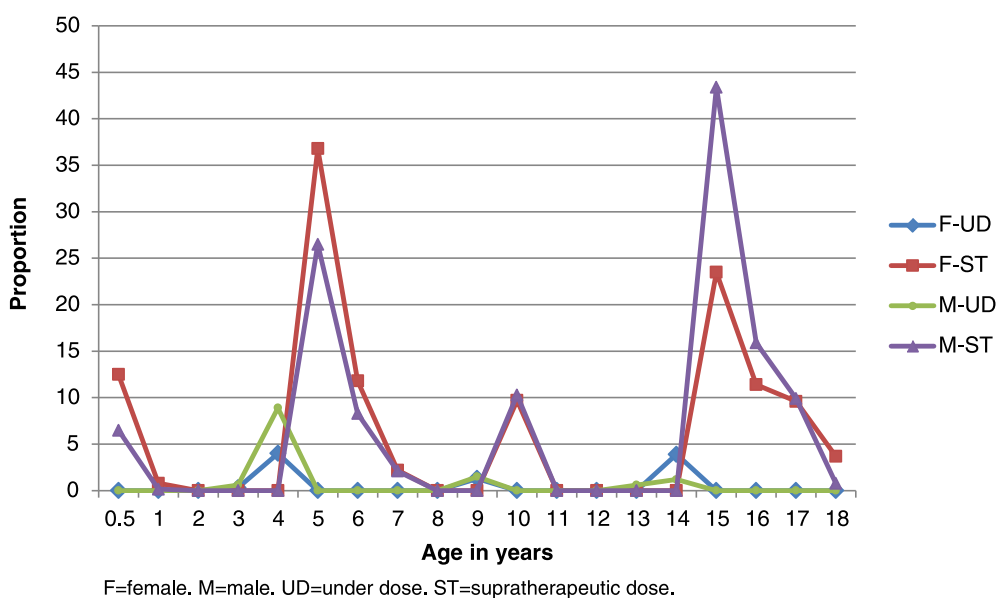

Fig. 4 The proportions of females and males who would receive either an under $(<0.15 \mathrm{mg}$ base $/ \mathrm{kg}$ ) or supratherapeutic $(>0.38 \mathrm{mg}$ base $/ \mathrm{kg})$ dose of primaquine

Although our data are unsuitable as reference data to construct a weight-for-age "growth chart" for Cambodia as a whole, we did construct "growth curves" using Box Cox modelling, which enabled us to calculate the $\mathrm{mg}$ base $/ \mathrm{kg}$ dose of PQ that individuals would receive. Our weight-forage curve is similar to those of Cambodia, Laos, and Myanmar constructed by Hayes et al. [22]. These countries are also affected by ARPf and share similar G6PDd variants with Cambodia [86]. Thus, our SLDPQ regimen is generalisable to two of Cambodia's GMS neighbours.

There are some limitations to our study. Children aged $<5$ years and women of child-bearing age predominated because most of these data came from the DHS survey. Previous databases have suffered from having fewer individuals aged 5-15 years [21] and anthropometric data from several of the databases used by Hayes et al. [22] were also somewhat patchy. Our database had relatively fewer data in the 5-15 years age group, with individual ages numbering between 200 and 300. In common with other malaria-endemic countries, individuals often do not know their exact dates of birth but are usually able to estimate their ages reasonably well. This is more important for children and help with age determination can be obtained from "Road to Health" charts and, in some countries, national ID cards.

Although we believe our SLDPQ regimen is accurate based on current knowledge of PQ's PK and PD characteristics, new knowledge could result in its revision. Several significant knowledge gaps exist, notably, the lack of PK OM data, dose-response curves for mosquito infectivity and red cell haemolysis, and important PK parameters such as the maximum concentration or area under the concentration-time curve. There are no PQ PK data in children aged $<5$ years. Yet, these data are crucial to establish whether the target PQ dose of $0.25 \mathrm{mg}$ base $/ \mathrm{kg}$ applies to this vulnerable group.

Our knowledge of PQ drug interactions is also limited. Increased awareness of drugs that could potentiate the haemolytic toxicity of SLDPQ is especially important either by a metabolic interaction at the CYP level

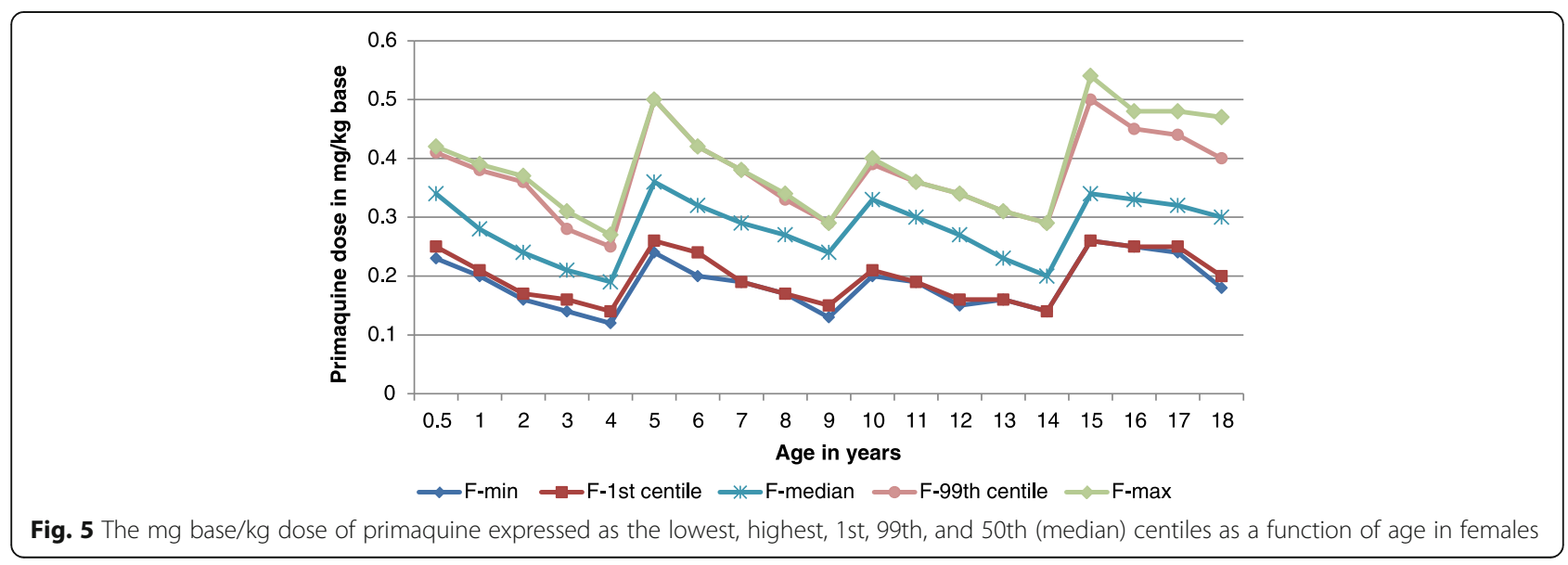




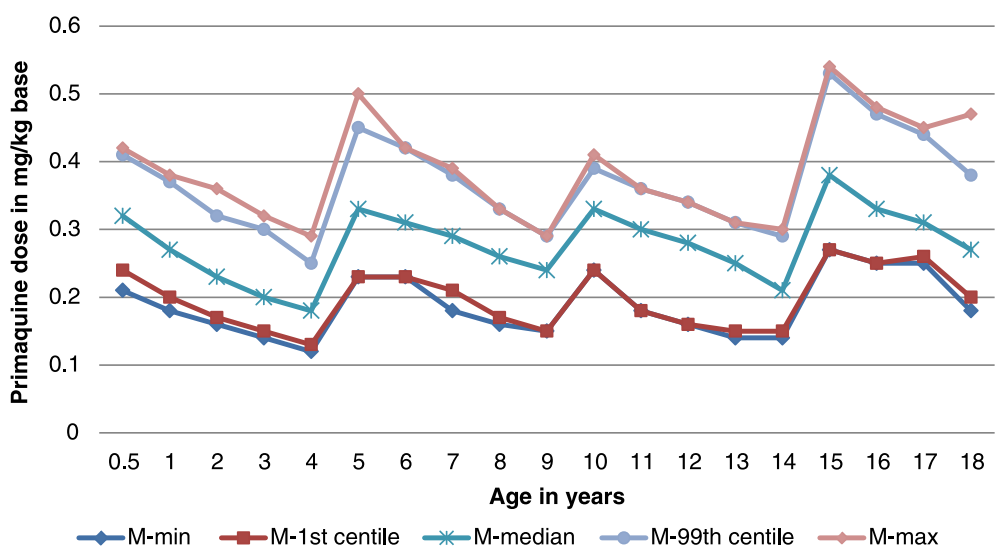

Fig. 6 The $\mathrm{mg}$ base/kg dose of primaquine expressed as the lowest, highest, 1st, 99th, and 50th (median) centiles as a function of age in males

or by direct red blood cell toxicity. Once SLDPQ is deployed, good pharmacovigilance systems will need to be in place so confidence in SLDPQ by the populace remains high. This is especially so when SLDPQ is used as MDA because healthy individuals will take a drug with the intention of a community rather than individual benefit, but which could result in toxicity for individuals. Moreover, accidental exposure to PQ in pregnancy can be expected and is another critical area of pharmacovigilance.

The effect over time of the widespread use of SLDPQ on gametocyte sensitivity and $P$. vivax liver hypnozoites is unknown. This would need to be studied to enable malaria control programmes to adapt their strategies if PQ resistance were to develop.

Currently, in Cambodia, approximately $30 \%$ of all malaria treatments are given by village malaria workers. They will need to be trained on how to administer SLDPQ, what advice to give to recipients regarding PQ toxicity, and how to manage visibly malnourished or overweight children. As countries move towards malaria elimination and adopt MDA with SLDPQ, it is clear that the efficient dosing of large numbers of individuals is best achieved using an age-based regimen, much in the same way as anthelminthic MDA is done. Coordination between different MDA programmes would be essential.

Table 2 A suggested weight-based dosing scheme for single low-dose primaquine

\begin{tabular}{lll}
\hline Weight in $\mathrm{kg}$ & $\begin{array}{l}\text { Dose of primaquine } \\
\text { base in } \mathrm{mg}\end{array}$ & $\begin{array}{l}\text { Dose of primaquine } \\
\text { base in } \mathrm{mg} / \mathrm{kg}\end{array}$ \\
\hline $5-14.99$ & 2.5 & $0.5-0.17$ \\
$15-29.99$ & 5 & $0.33-0.17$ \\
$30-39.99$ & 7.5 & $0.25-0.19$ \\
$40-79.99$ & 15 & $0.38-0.18$ \\
$80-109.9$ & 20 & $0.25-0.18$ \\
\hline
\end{tabular}

Few manufacturers produce PQ to international Good Manufacturing Practice. Current tablet strengths are limited to 7.5 and $15 \mathrm{mg}$ of PQ base, which is quite inadequate. Moreover, there are no PQ formulations for children and PQ has a very bitter taste. Options to increase palatability include sweetened dispersible tablets, as has been developed for AL [87], granules, mini tablets, and gel coating $[88,89]$. These are issues of great importance that could substantially affect access to PQ and the success of malaria elimination. If regional- or country-specific, age-based dosing regimens could be designed that use a limited number of the same tablet strengths, this would be a strong argument in convincing pharmaceutical companies to engage positively in malaria elimination.

South American populations weigh more than their African counterparts, who in turn weigh more than South East Asian/Western Pacific populations [22]. Therefore, our SLDPQ regimen cannot be generalised to South America and Africa. Caution is also needed for the Middle East and parts of west Asia where anthropometric characteristics need further study and where the most severe G6PDd variant - Mediterranean - is not uncommon [33].

Our SLDPQ regimen has four age-dosing groups and we have proposed a weight-based regimen with four (five if very heavy individuals are separated off) weight bands. Neither regimen fits in neatly with commonly used ACTs. Artesunate-mefloquine, artesunate-amodiaquine (not used currently in Cambodia), and DHAPP have four, four, and six age-based dosing regimens, respectively, and AL and artesunate-pyronaridine both have four weight-based regimens. This underlies the need for good training when the age-based PQ regimen is eventually deployed [20].

\section{Conclusions}

We have designed an age-based regimen for SLDPQ that would be suitable for use in Cambodia and other GMS 
countries. This regimen should be deployed on a research footing to see if it is acceptable to health workers and patients. Other SLDPQ regimens need to be developed for South America, Africa, and the Middle East/west Asia based on evidence of efficacy and tolerability. Pharmaceutical companies need to engage enthusiastically in malaria elimination.

\section{Additional files}

Additional file 1: Figure S1. Weight-for-age modelled as a growth curve. (DOCX $46 \mathrm{~kb}$ )

Additional file 2: Figure S2. Scattergram of the modelled weight-forage distributions for different groups in the database. (JPG 50 kb)

\section{Abbreviations}

ACT: artemisinin combination therapy; AHA: acute haemolytic anaemia; AL: artemether lumefantrine; ARPf: artemisinin-resistant Plasmodium falciparum; CNS: central nervous system; CPQ: carboxyprimaquine; CYP: cytochrome; D: day; DHAPP: dihydroartemisinin-piperaquine; DHS: Demographic Health Survey; G6PDd: glucose-6-phosphate dehydrogenase deficiency; GMS: Greater Mekong Subregion; Hb: haemoglobin; MAO: monoamine oxidase; MDA: mass drug administration; MetHb: methaemoglobinaemia; MTB: minimum transmission blocking; OM: oxidative metabolite; PD: pharmacodynamics;

PK: pharmacokinetics; PQ: primaquine; SLDPQ: single low-dose primaquine; WHO: World Health Organization

\section{Acknowledgments}

We acknowledge with gratitude the Demographic Health Survey of USAID for permission to download data from their 2014 survey in Cambodia. WRJT was partly supported by France Expertise International through the $5 \%$ initiative as a consultant to Centre National de Malariologie in operational research; he expresses "ses profonds remerciements au peuple français." NJW is a Wellcome Trust Principal Fellow. Data contributed by RMF were obtained from studies funded by the Intramural Research Program of the US National Institute of Allergy and Infectious Diseases, National Institutes of Health.

\section{Funding}

This study received no funding.

\section{Authors' contributions}

WRJT hatched the original idea and oversaw the study with RL. MV constructed the growth curve. WRJT, HKN, and MV analysed the data and wrote the first draft of the paper with contributions from RL. MD, RT, $A D$, SYT, CS, KN, PB, AT, AR-F, RMF, KS, and MS provided raw data. NJW provided important scientific input early on and critically reviewed the first draft. DM, AT, RMF, and AMD critically reviewed the paper. All co-authors have seen the final draft of the paper. All authors read and approved the fina manuscript.

\section{Competing interests}

The authors declare that they have no competing interests.

\section{Author details}

${ }^{1}$ National Center for Parasitology, Entomology and Malaria Control, Corner St. 92, Trapeng Svay Village, Sangkat Phnom Penh, Thmei, Khan Sen Sok, Phnom Penh, Cambodia. ${ }^{2}$ Mahidol Oxford Tropical Medicine Research Unit (MORU), 420/6 Rajvithi Road, Rajthevee, Bangkok 10400, Thailand. ${ }^{3}$ Oxford Centre for Tropical Medicine and Global Health, Nuffield Department of Medicine Research Building, University of Oxford, Old Road Campus, Roosevelt Drive, Oxford OX3 7FZ, UK. ${ }^{4}$ MSF Belgium Cambodia Malaria Program, \#19, Street 388, Sangkat Tuol Svay Prey, Khan Chamkarmon, PO Box 1933, Phnom Penh, Cambodia. ${ }^{5}$ University Research Co., LLC, MK Building, House \#10 (2nd floor), St. 214, Chey Chumneas, Daun Penh, Phnom Penh, Cambodia. 'University Research Co., LLC Washington DC: 7200 Wisconsin Ave, Bethesda, MD 20814, USA. ${ }^{7}$ Institut Pasteur du Cambodge, 5 Monivong Boulevard, PO Box 983, Phnom Penh 12201, Cambodia. ${ }^{8}$ Malaria Consortium, House \#91 Street 95,
Boeung Trabek, Chamkar Morn, Phnom Penh, Cambodia. ' ${ }^{2}$ Laboratory of Malaria and Vector Research, National Institute of Allergy and Infectious Diseases, National Institutes of Health, Rockville, MD 20852, USA. ${ }^{10} \mathrm{FHI} 360$ Cambodia Office, \#03, Street 330 Boeung Keng Kang III Khan Chamkamon, PO Box: 2586, Phnom Penh, Cambodia. ${ }^{11}$ Centre de Médecine Humanitaire, Hôpitaux Universitaires de Genève, Genève, Switzerland.

Received: 18 April 2016 Accepted: 20 September 2016

Published online: 27 October 2016

\section{References}

1. White NJ, Qiao LG, Qi G, Luzzatto L. Rationale for recommending a lower dose of primaquine as a Plasmodium falciparum gametocytocide in populations where G6PD deficiency is common. Malar J. 2012;11:418.

2. WHO Malaria Policy Advisory Committee and Secretariat. Malaria Policy Advisory Committee to the WHO: conclusions and recommendations of September 2012 meeting. Malar J. 2012;11:424.

3. Noedl H, Se Y, Schaecher K, Smith BL, Socheat D, Fukuda MM. Artemisinin Resistance in Cambodia 1 (ARC1) Study Consortium. Evidence of artemisinin-resistant malaria in western Cambodia. N Engl J Med. 2008;359(24):2619-20.

4. Dondorp AM, Nosten F, Yi P, Das D, Phyo AP, Tarning J, Lwin KM, Ariey F, Hanpithakpong W, Lee SJ, et al. Artemisinin resistance in Plasmodium falciparum malaria. N Engl J Med. 2009:361(5):455-67.

5. Ariey F, Witkowski B, Amaratunga C, Beghain J, Langlois AC, Khim N, Kim S, Duru $V$, Bouchier C, Ma L, et al. A molecular marker of artemisinin-resistant Plasmodium falciparum malaria. Nature. 2014;505(7481):50-5.

6. Phyo AP, Nkhoma S, Stepniewska K, Ashley EA, Nair S, McGready R, Ler Moo C, Al-Saai S, Dondorp AM, Lwin KM. Emergence of artemisinin-resistant malaria on the western border of Thailand: a longitudinal study. Lancet. 2012:379(9830):1960-6

7. Hien TT, Thuy-Nhien NT, Phu NH, Boni MF, Thanh NV, Nha-Ca NT, Thai LH, Thai CQ, Toi PV, Thuan PD, et al. In vivo susceptibility of Plasmodium falciparum to artesunate in Binh Phuoc Province, Vietnam. Malar J. 2012;11(1):355.

8. Ashley EA, Dhorda M, Fairhurst RM, Amaratunga C, Lim P, Suon S, Sreng S, Anderson JM, Mao S, Sam B, et al. Spread of artemisinin resistance in Plasmodium falciparum malaria. N Engl J Med. 2014;371(5):411-23.

9. Amaratunga C, Sreng S, Suon S, Phelps ES, Stepniewska K, Lim P, Zhou C, Mao S, Anderson JM, Lindegardh N, et al. Artemisinin-resistant Plasmodium falciparum in Pursat province, western Cambodia: a parasite clearance rate study. Lancet Infect Dis. 2012;12(11):851-8.

10. Tun KM, Imwong M, Lwin KM, Win AA, Hlaing TM, Hlaing T, Lin K, Kyaw MP, Plewes K, Faiz MA, et al. Spread of artemisinin-resistant Plasmodium falciparum in Myanmar: a cross-sectional survey of the K13 molecular marker. Lancet Infect Dis. 2015;15(4):415-21.

11. Leang R, Barrette A, Bouth DM, Menard D, Abdur R, Duong S, Ringwald P. Efficacy of dihydroartemisinin-piperaquine for treatment of uncomplicated Plasmodium falciparum and Plasmodium vivax in Cambodia, 2008 to 2010. Antimicrob Agents Chemother. 2013:57(2):818-26.

12. Leang R, Taylor WR, Bouth DM, Song L, Tarning J, Char MC, Kim S, Witkowski B, Duru V, Domergue A, et al. Evidence of Plasmodium falciparum malaria multidrug resistance to artemisinin and piperaquine in western Cambodia: dihydroartemisinin-piperaquine open-label multicenter clinical assessment. Antimicrob Agents Chemother. 2015;59(8):4719-26.

13. Spring MD, Lin JT, Manning JE, Vanachayangkul $P$, Somethy $S$, Bun $R$, Se $Y$, Chann S, Ittiverakul M, Sia-Ngam P, et al. Dihydroartemisinin-piperaquine failure associated with a triple mutant including kelch13 C580Y in Cambodia: an observational cohort study. Lancet Infect Dis. 2015;15(6):683-91.

14. Amaratunga C, Lim P, Suon S, Sreng S, Mao S, Sopha C, Sam B, Dek D, Try V, Amato $R$, et al. Dihydroartemisinin-piperaquine resistance in Plasmodium falciparum malaria in Cambodia: a multisite prospective cohort study. Lancet Infect Dis. 2016:16(3):357-65.

15. Kheng S, Muth S, Taylor WR, Tops N, Kosal K, Sothea K, Souy P, Kim S, Char CM, Vanna $C$, et al. Tolerability and safety of weekly primaquine against relapse of Plasmodium vivax in Cambodians with glucose-6-phosphate dehydrogenase deficiency. BMC Med. 2015:13:203.

16. Helmy SA. Tablet splitting: is it worthwhile? Analysis of drug content and weight uniformity for half tablets of 16 commonly used medications in the outpatient setting. J Manag Care Spec Pharm. 2015;21(1):76-86. 
17. O'Connell KA, Samandari G, Phok S, Phou M, Dysoley L, Yeung S, Allen H, Littrell M. "Souls of the ancestor that knock us out" and other tales. A qualitative study to identify demand-side factors influencing malaria case management in Cambodia. Malar J. 2012;11:335.

18. Yeung S, Van Damme W, Socheat D, White NJ, Mills A. Access to artemisinin combination therapy for malaria in remote areas of Cambodia. Malar J. 2008;7:96.

19. Xu JW, Xu QZ, Liu H, Zeng YR. Malaria treatment-seeking behaviour and related factors of Wa ethnic minority in Myanmar: a cross-sectional study. Malar J. 2012;11:417.

20. Marsh VM, Mutemi WM, Willetts A, Bayah K, Were S, Ross A, Marsh K. Improving malaria home treatment by training drug retailers in rural Kenya. Trop Med Int Health. 2004;9(4):451-60.

21. Taylor W, Terlouw DJ, Olliaro PL, White NJ, Brasseur P, ter Kuile FO. Use of weight-for-age-data to optimize tablet strength and dosing regimens for a new fixed-dose artesunate-amodiaquine combination for treating falciparum malaria. Bull World Health Organ. 2006;84(12):956-64.

22. Hayes DJ, van Buuren S, Ter Kuile FO, Stasinopoulos DM, Rigby RA, Terlouw DJ. Developing regional weight-for-age growth references for malariaendemic countries to optimize age-based dosing of antimalarials. Bull World Health Organ. 2015;93(2):74-83.

23. Dick GW, Bowles RV. The value of plasmoquine as a gametocide in subtertian malaria. Trans R Soc Trop Med Hyg. 1947;40(4):447-50.

24. Mackerras MJ, Ercole QN. Some observations on the action of quinine, atebrin, and plasmoquine on Plasmodium vivax. Trans R Soc Trop Med Hyg. 1949;42(5):443-54

25. Dicko A, Brown JM, Diawara H, Baber I, Mahamar A, Soumare HM, Sanogo K, Koita F, Keita S, Traore SF, et al. Primaquine to reduce transmission of Plasmodium falciparum malaria in Mali: a single-blind, dose-ranging, adaptive randomised phase 2 trial. Lancet Infect Dis. 2016;16(6):674-84

26. White NJ, Ashley EA, Recht J, Delves MJ, Ruecker A, Smithuis FM, Eziefula AC, Bousema T, Drakeley C, Chotivanich K, et al. Assessment of therapeutic responses to gametocytocidal drugs in Plasmodium falciparum malaria. Malar J. 2014;13:483.

27. Burgess RW, Bray RS. The effect of a single dose of primaquine on the gametocytes, gametogony and sporogony of Laverania falciparum. Bull World Health Organ. 1961;24:451-6.

28. Rieckmann KH, McNamara JV, Kass L, Powell RD. Gametocytocidal and sporontocidal effects of primaquine upon two strains of Plasmodium falciparum. Mil Med. 1969;134(10):802-19.

29. Song J, Socheat D, Tan B, Dara P, Deng C, Sokunthea S, Seila S, Ou F, Jian H, Li G. Rapid and effective malaria control in Cambodia through mass administration of artemisinin-piperaquine. Malar J. 2010;9:57.

30. Maude RJ, Socheat D, Nguon C, Saroth P, Dara P, Li G, Song J, Yeung S, Dondorp AM, Day NP, et al. Optimising strategies for Plasmodium falciparum malaria elimination in Cambodia: primaquine, mass drug administration and artemisinin resistance. PLoS One. 2012;7(5):e37166.

31. Ashley EA, Recht J, White NJ. Primaquine: the risks and the benefits. Malar J. $2014 ; 13: 418$

32. Luzzatto L, Seneca E. G6PD deficiency: a classic example of pharmacogenetics with on-going clinical implications. Br J Haematol. 2014;164(4):469-80.

33. Beutler E. G6PD: population genetics and clinical manifestations. Blood Rev. 1996;10(1):45-52.

34. Alving AS, Johnson CF, Tarlov AR, Brewer GJ, Kellermeyer RW, Carson PE. Mitigation of the haemolytic effect of primaquine and enhancement of its action against exoerythrocytic forms of the Chesson strain of Piasmodium vivax by intermittent regimens of drug administration: a preliminary report. Bull World Health Organ. 1960;22:621-31.

35. George JN, Sears DA, McCurdy PR, Conrad ME. Primaquine sensitivity in Caucasians: hemolytic reactions induced by primaquine in G-6-PD deficient subjects. J Lab Clin Med. 1967;70(1):80-93.

36. Everett WD, Yoshida A, Pearlman E. Hemoglobin E and glucose-6-phosphate deficiency in the Khmer Air Force (Cambodia). Am J Trop Med Hyg. 1977;26(4):597-601.

37. Bancone G, Chu CS, Somsakchaicharoen R, Chowwiwat N, Parker DM, Charunwatthana P, White NJ, Nosten FH. Characterization of G6PD genotypes and phenotypes on the northwestern Thailand-Myanmar border. PLoS One. 2014;9(12):e116063.

38. Chan TK, Todd D, Tso SC. Drug-induced haemolysis in glucose-6-phosphate dehydrogenase deficiency. Br Med J. 1976;2(6046):1227-9.
39. Kim S, Nguon C, Guillard B, Duong S, Chy S, Sum S, Nhem S, Bouchier C, Tichit M, Christophel E, et al. Performance of the CareStart G6PD deficiency screening test, a point-of-care diagnostic for primaquine therapy screening. PLoS One. 2011;6(12):e28357.

40. Khim N, Benedet C, Kim S, Kheng S, Siv S, Leang R, Lek S, Muth S, Chea N, Chuor CM, et al. G6PD deficiency in Plasmodium falciparum and Plasmodium vivax malaria-infected Cambodian patients. Malar J. 2013;12(1):171.

41. Taylor WR, Widjaja H, Basri H, Tjitra E, Ohrt C, Taufik T, Baso S, Hoffman SL, Richie TL. Haemoglobin dynamics in Papuan and non-Papuan adults in northeast Papua, Indonesia, with acute, uncomplicated vivax or falciparum malaria. Malar J. 2013;12:209.

42. Bancone G, Chowwiwat N, Somsakchaicharoen R, Poodpanya L, Moo PK, Gornsawun G, Kajeechiwa L, Thwin MM, Rakthinthong S, Nosten S, et al. Single low dose primaquine $(0.25 \mathrm{mg} / \mathrm{kg})$ does not cause clinically significant haemolysis in G6PD deficient subjects. PLoS One. 2016;11(3):e0151898.

43. Hockwald RS, Arnold J, Clayman CB, Alving AS. Toxicity of primaquine in Negroes. J Am Med Assoc. 1952;149(17):1568-70.

44. Clayman CB, Arnold J, Hockwald RS, Yount Jr EH, Edgcomb JH, Alving AS. Toxicity of primaquine in Caucasians. J Am Med Assoc. 1952;149(17):1563-8.

45. Fryauff DJ, Baird JK, Basri H, Sumawinata I, Purnomo, Richie TL, Ohrt CK, Mouzin E, Church CJ, Richards AL, et al. Randomised placebo-controlled trial of primaquine for prophylaxis of falciparum and vivax malaria. Lancet. 1995;346(8984):1190-3.

46. Cuong BT, Binh VQ, Dai B, Duy DN, Lovell CM, Rieckmann KH, Edstein MD. Does gender, food or grapefruit juice alter the pharmacokinetics of primaquine in healthy subjects? Br J Clin Pharmacol. 2006;61(6):682-9.

47. Mihaly GW, Ward SA, Edwards G, Nicholl DD, Orme ML, Breckenridge AM. Pharmacokinetics of primaquine in man. I. Studies of the absolute bioavailability and effects of dose size. Br J Clin Pharmacol. 1985;19(6):745-50.

48. Pybus BS, Sousa JC, Jin X, Ferguson JA, Christian RE, Barnhart R, Vuong C, Sciotti RJ, Reichard GA, Kozar MP, et al. CYP450 phenotyping and accurate mass identification of metabolites of the 8-aminoquinoline, anti-malarial drug primaquine. Malar J. 2012;11:259.

49. Constantino L, Paixao P, Moreira R, Portela MJ, Do Rosario VE, lley J. Metabolism of primaquine by liver homogenate fractions. Evidence for monoamine oxidase and cytochrome P450 involvement in the oxidative deamination of primaquine to carboxyprimaquine. Exp Toxicol Pathol. 1999;51(4-5):299-303.

50. Thompson SF, Fraser IM, Strother A, Bull BS. Change of deformability and Heinz body formation in G6PD-deficient erythrocytes treated with 5-hydroxy-6desmethylprimaquine. Blood Cells. 1989;15(2):443-52. discussion 453-444.

51. Bowman ZS, Jollow DJ, McMillan DC. Primaquine-induced hemolytic anemia: role of splenic macrophages in the fate of 5-hydroxyprimaquinetreated rat erythrocytes. J Pharmacol Exp Ther. 2005;315(3):980-6.

52. Ganesan S, Chaurasiya ND, Sahu R, Walker LA, Tekwani BL. Understanding the mechanisms for metabolism-linked hemolytic toxicity of primaquine against glucose 6-phosphate dehydrogenase deficient human erythrocytes: evaluation of eryptotic pathway. Toxicology. 2012;294(1):54-60.

53. Bolchoz $\sqcup$, Budinsky RA, McMillan DC, Jollow DJ. Primaquine-induced hemolytic anemia: formation and hemotoxicity of the arylhydroxylamine metabolite 6-methoxy-8-hydroxylaminoquinoline. J Pharmacol Exp Ther. 2001;297(2):509-15.

54. Bolchoz $\sqcup$, Morrow JD, Jollow DJ, McMillan DC. Primaquine-induced hemolytic anemia: effect of 6-methoxy-8-hydroxylaminoquinoline on rat erythrocyte sulfhydryl status, membrane lipids, cytoskeletal proteins, and morphology. J Pharmacol Exp Ther. 2002;303(1):141-8.

55. Liu H, Tekwani BL, Nanayakkara NP, Walker LA, Doerksen RJ. Methemoglobin generation by 8-aminoquinolines: effect of substitution at 5-position of primaquine. Chem Res Toxicol. 2013;26(12):1801-9.

56. Allahyari R, Strother A, Fraser IM, Verbiscar AJ. Synthesis of certain hydroxy analogues of the antimalarial drug primaquine and their in vitro methemoglobin-producing and glutathione-depleting activity in human erythrocytes. J Med Chem. 1984;27(3):407-10.

57. Bennett JW, Pybus BS, Yadava A, Tosh D, Sousa JC, McCarthy WF, Deye G, Melendez V, Ockenhouse CF. Primaquine failure and cytochrome P-450 2D6 in Plasmodium vivax malaria. N Engl J Med. 2013;369(14):1381-2.

58. Chotivanich K, Sattabongkot J, Udomsangpetch R, Looareesuwan S, Day NP, Coleman RE, White NJ. Transmission-blocking activities of quinine, primaquine, and artesunate. Antimicrob Agents Chemother. 2006;50(6):1927-30 
59. Portela MJ, Moreira R, Valente E, Constantino L, lley J, Pinto J, Rosa R, Cravo P, do Rosario VE. Dipeptide derivatives of primaquine as transmission-blocking antimalarials: effect of aliphatic side-chain acylation on the gametocytocidal activity and on the formation of carboxyprimaquine in rat liver homogenates. Pharm Res. 1999;16(6):949-55.

60. Ingelman-Sundberg M. Genetic polymorphisms of cytochrome P450 2D6 (CYP2D6): clinical consequences, evolutionary aspects and functional diversity. The pharmacogenomics journal. 2005;5(1):6-13.

61. Crews KR, Gaedigk A, Dunnenberger HM, Leeder JS, Klein TE, Caudle KE, Haidar CE, Shen DD, Callaghan JT, Sadhasivam S, et al. Clinical Pharmacogenetics Implementation Consortium guidelines for cytochrome P450 2D6 genotype and codeine therapy: 2014 update. Clin Pharmacol Ther. 2014:95(4):376-82.

62. Owen RP, Sangkuhl K, Klein TE, Altman RB. Cytochrome P450 2D6. Pharmacogenet Genomics. 2009;19(7):559-62.

63. Staehli Hodel EM, Csajka C, Ariey F, Guidi M, Kabanywanyi AM, Duong S, Decosterd LA, Olliaro P, Beck HP, Genton B. Effect of single nucleotide polymorphisms in cytochrome P450 isoenzyme and N-acetyltransferase 2 genes on the metabolism of artemisinin-based combination therapies in malaria patients from Cambodia and Tanzania. Antimicrob Agents Chemother. 2013;57(2):950-8.

64. Kurose K, Sugiyama E, Saito Y. Population differences in major functional polymorphisms of pharmacokinetics/pharmacodynamics-related genes in Eastern Asians and Europeans: implications in the clinical trials for novel drug development. Drug Metab Pharmacokinet. 2012;27(1):9-54.

65. Sistonen J, Sajantila A, Lao O, Corander J, Barbujani G, Fuselli S. CYP2D6 worldwide genetic variation shows high frequency of altered activity variants and no continental structure. Pharmacogenet Genomics. 2007;17(2):93-101.

66. Moore BR, Salman S, Benjamin J, Page-Sharp M, Robinson LJ, Waita E, Batty KT, Siba P, Mueller I, Davis TM, et al. Pharmacokinetic properties of singledose primaquine in Papua New Guinean children: feasibility of abbreviated high-dose regimens for radical cure of vivax malaria. Antimicrob Agents Chemother. 2014;58(1):432-9.

67. Pukrittayakamee S, Tarning J, Jittamala P, Charunwatthana P, Lawpoolsri S, Lee SJ, Hanpithakpong W, Hanboonkunupakarn B, Day NP, Ashley EA, et al. Pharmacokinetic interactions between primaquine and chloroquine. Antimicrob Agents Chemother. 2014;58(6):3354-9.

68. Hanboonkunupakarn B, Ashley EA, Jittamala P, Tarning J, Pukrittayakamee S, Hanpithakpong W, Chotsiri P, Wattanakul T, Panapipat S, Lee SJ, et al. Openlabel crossover study of primaquine and dihydroartemisinin-piperaquine pharmacokinetics in healthy adult thai subjects. Antimicrob Agents Chemother. 2014;58(12):7340-6.

69. Edwards G, McGrath CS, Ward SA, Supanaranond W, Pukrittayakamee S, Davis TM, White NJ. Interactions among primaquine, malaria infection and other antimalarials in Thai subjects. Br J Clin Pharmacol. 1993;35(2):193-8.

70. Barnes KI, Little F, Smith PJ, Evans A, Watkins WM, White NJ. Sulfadoxinepyrimethamine pharmacokinetics in malaria: pediatric dosing implications. Clin Pharmacol Ther. 2006;80(6):582-96.

71. Tarning J, Chotsiri P, Jullien V, Rijken MJ, Bergstrand M, Cammas M, McGready R, Singhasivanon P, Day NP, White NJ, et al. Population pharmacokinetic and pharmacodynamic modeling of amodiaquine and desethylamodiaquine in women with plasmodium vivax malaria during and after pregnancy. Antimicrob Agents Chemother. 2012;56(11):5764-73.

72. Ward SA, Mihaly GW, Edwards G, Looareesuwan S, Phillips RE, Chanthavanich P, Warrell DA, Orme ML, Breckenridge AM. Pharmacokinetics of primaquine in man. II. Comparison of acute vs chronic dosage in Thai subjects. Br J Clin Pharmacol. 1985;19(6):751-5.

73. Bangchang KN, Songsaeng W, Thanavibul A, Choroenlarp P, Karbwang J. Pharmacokinetics of primaquine in G6PD deficient and G6PD normal patients with vivax malaria. Trans R Soc Trop Med Hyg. 1994;88(2):220-2.

74. Elmes NJ, Bennett SM, Abdalla H, Carthew TL, Edstein MD. Lack of sex effect on the pharmacokinetics of primaquine. Am J Trop Med Hyg. 2006;74(6):951-2.

75. Binh VQ, Chinh NT, Thanh NX, Cuong BT, Quang NN, Dai B, Travers T, Edstein MD. Sex affects the steady-state pharmacokinetics of primaquine but not doxycycline in healthy subjects. Am J Trop Med Hyg. 2009;81(5):747-53.

76. Jittamala P, Pukrittayakamee S, Ashley EA, Nosten F, Hanboonkunupakarn B, Lee SJ, Thana P, Chairat K, Blessborn D, Panapipat S, et al. Pharmacokinetic interactions between primaquine and pyronaridine-artesunate in healthy adult Thai subjects. Antimicrob Agents Chemother. 2015;59(1):505-13.

77. Singhasivanon V, Chongsuphajaisiddhi T, Sabchareon A, Attanath P, Webster HK, Edstein MD, Lika ID. Pharmacokinetic study of mefloquine in Thai children aged 5-12 years suffering from uncomplicated falciparum malaria treated with MSP or MSP plus primaquine. Eur J Drug Metab Pharmacokinet. 1994;19(1):27-32.

78. Wright EM, Royston P. Simplified estimation of age-specific reference intervals for skewed data. Stat Med. 1997;16(24):2785-803.

79. Rigby RA, Stasinopoulos DM. Smooth centile curves for skew and kurtotic data modelled using the Box-Cox power exponential distribution. Stat Med. 2004;23(19):3053-76.

80. Ogden CL, Kuczmarski RJ, Flegal KM, Mei Z, Guo S, Wei R, Grummer-Strawn LM, Curtin LR, Roche AF, Johnson CL. Centers for Disease Control and Prevention 2000 growth charts for the United States: improvements to the 1977 National Center for Health Statistics version. Pediatrics. 2002;109(1):45-60.

81. WHO Multicentre Growth Reference Study Group. WHO Child Growth Standards based on length/height, weight and age. Acta Paediatr. 2006;450:76-85.

82. Hoyer S, Nguon S, Kim S, Habib N, Khim N, Sum S, Christophel EM, Bjorge S, Thomson A, Kheng S, et al. Focused Screening and Treatment (FSAT): a PCR-based strategy to detect malaria parasite carriers and contain drug resistant P. falciparum, Pailin, Cambodia. PLoS One. 2012;7(10):e45797.

83. Canier L, Khim N, Kim S, Sluydts V, Heng S, Dourng D, Eam R, Chy S, Khean C, Loch $\mathrm{K}$, et al. An innovative tool for moving malaria PCR detection of parasite reservoir into the field. Malar J. 2013;12:405.

84. Bosman P, Stassijns J, Nackers F, Canier L, Kim N, Khim S, Alipon SC, Chuor Char M, Chea N, Dysoley L, et al. Plasmodium prevalence and artemisininresistant falciparum malaria in Preah Vihear Province, Cambodia: a crosssectional population-based study. Malar J. 2014;13:394.

85. Imwong M, Nguyen TN, Tripura R, Peto TJ, Lee SJ, Lwin KM, Suangkanarat $P$, Jeeyapant A, Vihokhern B, Wongsaen K, et al. The epidemiology of subclinical malaria infections in South-East Asia: findings from crosssectional surveys in Thailand-Myanmar border areas, Cambodia, and Vietnam. Malar J. 2015;14:381.

86. Iwai K, Hirono A, Matsuoka H, Kawamoto F, Horie T, Lin K, Tantular IS, Dachlan YP, Notopuro H, Hidayah NI, et al. Distribution of glucose-6-phosphate dehydrogenase mutations in Southeast Asia. Hum Genet. 2001;108(6):445-9.

87. Abdulla S, Sagara I, Borrmann S, D'Alessandro U, Gonzalez R, Hamel M, Ogutu B, Martensson A, Lyimo J, Maiga $\mathrm{H}$, et al. Efficacy and safety of artemetherlumefantrine dispersible tablets compared with crushed commercial tablets in African infants and children with uncomplicated malaria: a randomised, single-blind, multicentre trial. Lancet. 2008;372(9652):1819-27.

88. Aleksovski A, Dreu R, Gasperlin M, Planinsek O. Mini-tablets: a contemporary system for oral drug delivery in targeted patient groups. Expert Opin Drug Deliv. 2015;12(1):65-84

89. El Edelbi R, Eksborg S, Lindemalm S. In situ coating makes it easier for children to swallow and tolerate tablets and capsules. Acta Paediatr. 2015;104(9):956-61.

\section{Submit your next manuscript to BioMed Central and we will help you at every step:}

- We accept pre-submission inquiries

- Our selector tool helps you to find the most relevant journal

- We provide round the clock customer support

- Convenient online submission

- Thorough peer review

- Inclusion in PubMed and all major indexing services

- Maximum visibility for your research

Submit your manuscript at www.biomedcentral.com/submit
Biomed Central 